mecrosis in leukaemia, Scand $f$ Haematol 1985;35: 354-7.

6 Knupp C, Pekala PH, Cornelius P. Extensive bone marrow necrosis in patients with cancer and tumor necrosis factor activity in plasma. Am $f$ Hematol 1988;29:215-21.

7 Harigaya K, Watanabe S, Watanabe Y, Kageyama K Natakaya K. Multiple bone marrow necrosis and disseminated intravascular coagulation. Arch Pathol Lab Med 1977;101:652-4.
8 Brown $\mathrm{CH}$. Bone marrow necrosis. A study of seventy cases. fohns Hopkins Med $\mathcal{f}_{1972 ; 131: 189-203}$

9 Sporn JR, Fallon MA. Recovery from widespread bone marrow necrosis occurring after chemotherapy for adult marrow necrosis occurring after chemotherapy for adult acute monocy $1992 ; 20: 224-6$.

10 Rustgi VK, Sacher RA, O'Brien P, Garagusi VF. Fatal disseminated cytomegalovirus infection in an apparently normal adult. Arch Intern Med 1983;143:372-3.

\title{
Pure red cell aplasia associated with malignant thymoma, myasthenia gravis, polyclonal large granular lymphocytosis and clonal thymic $\mathrm{T}$ cell expansion
}

\author{
S I Handa, K P Schofield, M Sivakumaran, M Short, R S H Pumphrey
}

\begin{abstract}
A case with the triad of pure red cell aplasia (PRCA), myasthenia gravis, and malignant thymoma is reported. There was a clonal proliferation of $T$ cells within the thymoma, as demonstrated by a $T$ cell antigen receptor (TCR) $\delta$ chain gene rearrangement. However, despite a large granular lymphocytosis, clonality could not be shown in the peripheral blood either before or after thymectomy. There was no evidence of human $T$ cell lymphotrophic virus type 7 (HTLV1) infection.

It is postulated that the clonal thymic $T$ cell population secreted cytokine(s), which stimulated the polyclonal proliferation of large granular lymphocytes, which in turn suppressed erythropoiesis. Thymectomy removed the stimulus to the large granular lymphocytes and hence there was a resurgence of erythropoiesis.
\end{abstract}

Department of

Haematology, North

Manchester General

Hospital Manchester $S$ I Handa

K P Schofield

Department of

Haematology,

Leicester Royal

Infirmary, Leicester

M Sivakumaran

Molecular

Haematology Unit,

Leeds General

Infirmary Leeds

M Short

N W Regional

Immunology Service,

St Mary's Hospital,

Manchester

R S H Pumphrey

Correspondence to:

Dr M Sivakumaran

DrM Sivakum

Department of

Hoyal Infirmary, Leicester Royal Infirmary.

Accepted for publication

9 February 1994

\section{$(\mathcal{F}$ Clin Pathol 1994;47:676-679)}

Pure red cell aplasia (PRCA) is characterised by normocytic anaemia, reticulocytopenia, and severe erythroid hypoplasia of the bone marrow associated with normal myeloid and megakaryocytic cell lines. ${ }^{1}$ It is divided into congenital and acquired categories, the latter being further subdivided into two subclasses-primary and secondary. About 50\% of patients with PRCA have a thymoma. Conversely, because PRCA is rare, it occurs in only $5 \%$ of patients with thymoma. ${ }^{2}$ There is also a well recognised association between thymomas and myasthenia gravis. However, the simultaneous occurrence of all three disorders is extremely rare. ${ }^{3}$ Some cases of socalled primary PRCA have large granular lymphocytic leukaemia. ${ }^{4}$ This is a relatively recently recognised condition characterised by a neoplastic proliferation of large granular lymphocytes.

\section{Case report}

A 73 year old man presented with a four week history of symptoms of anaemia. His blood count showed a haemoglobin of $41 \mathrm{~g} / 1$ with a mean corpuscular volume (MCV) of $100 \mathrm{fl}$, a mild lymphocytosis $\left(5 \cdot 7 \times 10^{9} / 1\right)$, and a normal platelet count. Serum vitamin B12 and folate concentrations were normal. A bone marrow aspirate confirmed a diagnosis of pure red cell aplasia. Although a chest radiograph showed changes of chronic airways disease only, a computed tomography scan of the thorax showed a soft tissue mass in the anterior mediastinum that was suspicious of thymoma. There was a polyclonal increase in globulins with raised IgG and IgM. A random blood glucose sample showed an increased concentration and a glucose tolerance test was consistent with diabetes mellitus. $\mathrm{He}$ was initially managed with blood transfusions.

A month after presentation, he developed a unilateral partial ptosis. $\mathrm{He}$ also admitted to intermittent diplopia, some leg weakness, and non-progressive dysphagia. On examination he had a left partial ptosis and bilateral shoulder abduction weakness on exercise. A tensilon test was positive. Antibodies to acetylcholine receptor were increased and he later developed antibodies to striated muscle. Myasthenia gravis was diagnosed and he was given Pyridostigmine.

While awaiting thymectomy, his peripheral blood lymphocyte count increased, reaching a peak of $12 \cdot 1 \times 10^{9} / 1$ of which about $30 \%$ were large granular lymphocytes. Immunophenotyping of the peripheral blood and bone marrow lymphocytes showed that about $70 \%$ were T cells ( $67 \%$ with $a \beta$ and $2 \%$ with $\gamma \delta \mathrm{T}$ cell antigen receptors). About $30 \%$ of the peripheral blood mononuclear cells were of the natural killer cell phenotype $(\mathrm{CD} 2+$, CD3-, CD7 +, CD16 +, CD57 + ). A monoclonal antibody panel containing seven antibodies against the variable regions of the TCR showed the peripheral blood $T$ lymphocytes to be polyclonal. Infection with HTLV 
1 was excluded by serological, western blotting and molecular studies.

Thymectomy was performed and a large $(13 \times 9 \times 7 \mathrm{~cm})$ lobulated tumour that had invaded the pericardium was resected. Histological examination showed a thymoma of mixed epithelial-lymphoid type which was confirmed by immunohistochemistry. In view of incomplete encapsulation and extension into mediastinal fat, it was regarded as malignant. Immunophenotyping of the lymphoid cells from the thymoma showed a normal thymus pattern $(\mathrm{CD} 3=30 \%, \mathrm{CD} 4=82 \%$, $\mathrm{CD} 8=77 \%, \quad \mathrm{CD} 1=77 \%, \quad \mathrm{CD} 2=97 \%$, CD5 $=27 \% ， \quad$ CD7 $=95 \% ， \quad$ CD38 $=95 \%$, $\mathrm{CD} 20=1 \%, \mathrm{CD} 23=1 \%, \mathrm{CD} 34=1 \%$ and $\mathrm{CD} 25=2 \%)$. $\mathrm{T}$ cell receptor gene rearrangement studies on the thymoma tissue revealed a clone with rearrangement of the $\delta$ gene (figure).

Within a few hours of surgery the peripheral blood lymphocyte count fell to within the normal range and remained there. The large granular lymphocytes fell to $12 \%$ of the total peripheral blood lymphocytes. There was a corresponding change in the bone marrow lymphocyte surface markers. Molecular studies on the peripheral blood lymphocytes using TCR $\beta$ chain constant region and $\gamma$ and $\delta$ chain joining region probes showed no evidence of monoclonal proliferation of $\mathrm{T}$ lymphocytes.

A bone marrow aspirate four weeks after surgery showed a resurgence of erythropoiesis and he became transfusion independent. He died about six months after initial presentation following a protracted stay in intensive care with lower respiratory tract infection. Though a necropsy was not carried out, cause of death was thought to be severe bronchopneumonia.

Methods

Initial screening tests for HTLV1 used both
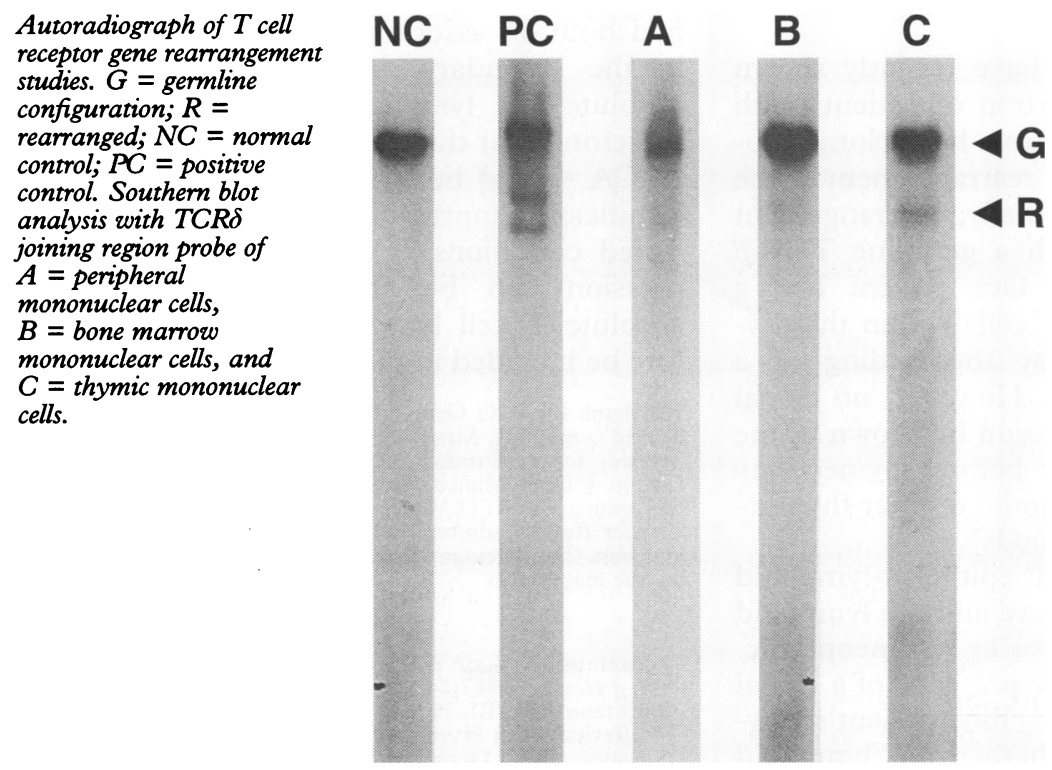

the Abbott enzyme immunoassay (EIA) (Abbott Diagnostics, Maidenhead, Berks) and the Fuji Rebio Serodia HTLV1 particle agglutination test (Mast Laboratories Limited, Bootle, Merseyside). The HTLV1 western blot used was from Du Pont (UK) Limited, Stevenage, Herts. All tests were carried out following the manufacturers' protocols.

The presence of HTLV1 sequences was looked for by extracting DNA from the thymoma tissue by standard procedures using sodium dodecyl sulphate/Proteinase $\mathrm{K}$ digestion. The DNA was digested with EcoRI or SacI, separated on a $0.8 \%$ agarose gel, and transferred to GeneScreen membranes. These blots were probed with an 8.9 kilobase SacI fragment of the pMT2 clone which had been labelled with ${ }^{32} \mathrm{P}$ by the random priming method, and washed under conditions of high stringency. The blot was autoradiographed.

DNA from peripheral blood mononuclear cell preparations and thymic tissue was extracted using the phenol-chloroform method. DNA $(10 \mu \mathrm{g})$ was digested with $B a m \mathrm{HI}$ and Hind III restriction enzymes (and additionally with $E c o$ RI when these results were inconclusive) and the DNA fragments separated by $0.8 \%$ agarose gel electrophoresis. These were transferred to nitrocellulose membranes by vacuum blotting, ultraviolet light fixed, and hybridised with the following ${ }^{32} \mathrm{P}$-labelled probes: the constant TCR $\beta$ region (C $\beta)$, M13BIBIOBBI; the TCR $\gamma$ joining region, $\mathrm{pPH} 60$; and the TCR $\delta$ joining region, R21XH. Hybridised filters were washed and the radioactive signal monitored by autoradiography.

A suspension of thymic cells was prepared by macerating the thymic tissue. Purified thymic and bone marrow mononuclear cell suspensions were obtained by density gradient centrifugation with lymphocyte separation medium (ICN, Irvine). Peripheral blood samples were stained without separating the cells.

A monoclonal antibody panel was selected to identify specific differentiation antigens. $T$ cell receptor variable regions were studied using the Diversi-T TCR screening panel 1A ( $T$ cell Sciences, Cambridge, Massachusetts).

The cells were incubated with optimal concentrations of each monoclonal antibody (manufacturer's recommendations) for 30 minutes at $4^{\circ} \mathrm{C}$. The cells were then washed twice in Hanks' Balanced Salt Solution (Life Technologies, Paisley, Scotland) containing $0.1 \%$ sodium azide, and incubated for a further 30 minutes at $4^{\circ} \mathrm{C}$ with $10 \mu \mathrm{l}$ fluoresceinisothiocyanate conjugated affinity purified goat anti-mouse immunoglobulin (Becton Dickinson, Oxford). The cells were washed twice as before. The red cells in the whole blood samples were lysed and the leucocytes fixed using the Coulter Q-prep system (Coulter Electronics Limited, Luton, Beds), whereas the purified mononuclear cells were fixed using $1 \%$ paraformaldehyde.

Flow cytometric analysis was performed using a Coulter EPICS Profile II flow cytometer. 


\section{Discussion}

Pure red cell aplasia has been described in conjunction with numerous conditions, including immunological disorders (such as thymoma, haemolytic anaemia, connective tissue disorders), lymphoproliferative and stem cell disorders, pregnancy, nutritional deficiencies and thyroid carcinoma. ${ }^{15}$ On the other hand, neoplasms of the thymus are associated with more than 20 "parathymic" syndromes affecting about $40 \%$ of patients. The three most common associations are with myasthenia gravis, PRCA, and hypogammoglobulinaemia. ${ }^{2}$ A review of the published studies revealed 22 patients with the clinical triad of PRCA, myasthenia, and thymoma, and of these, in only 14 cases was thymic pathology documented. ${ }^{35}$

Starkebaum et al first provided preliminary evidence suggesting that large granular lymphocytic leukaemia may be associated with infection with a retrovirus related to HLTV1. ${ }^{6}$ Subsequently, Levitt et al provided very convincing evidence of HTLV1 infection in a patient with large granular lymphocytic leukaemia, raising the possibility of an aetiological link between them. ${ }^{7}$ More relevant to our case, however, is the finding that Ono et al had earlier shown retrovirus-like particles in all cases of human thymomas and thymus hyperplasias examined by electron microscopy. ${ }^{8}$ They also provided additional convincing evidence of retroviral infection in these patients and suggested that this may be involved in the genesis of the thymic disorders.

Several humoral as well as cell mediated mechanisms have been demonstrated in both primary and secondary PRCA except in B CLL where $T$ cell suppression primarily accounts for the red cell aplasia. ${ }^{9} \mathrm{~A}$ case has been described in which it was shown that only the cell adherent layer of the bone marrow, containing mostly macrophages, was implicated in the pathogenesis of the PRCA. ${ }^{10}$ In large granular lymphocytic leukaemia a direct inhibitory effect of abnormal large granular lymphocytes on erythropoiesis in vitro has been shown in some patients with associated PRCA. ${ }^{4}$

Several investigators have recently shown that a significant proportion of patients with large granular lymphocytosis have clonal proliferations, evidenced by rearrangement of the TCR genes. ${ }^{4510}$ Occasionally, rearrangement of the TCR $\gamma$ gene with a germline TCR $\beta$ gene has been found. Our patient had a clonal proliferation of $T$ cells within the thymoma, as evidenced by the finding of a rearranged TCR $\delta$ gene. However, no clonal proliferation of $\mathrm{T}$ cells could be shown in the peripheral blood either before thymectomy (by immunological methods) or after thymectomy (by molecular methods).

Thymomas of mixed epithelial-lymphoid type are epithelial in nature and the lymphoid element is usually reactive or non-neoplastic. Having demonstrated the presence of a clonal lymphoid population in this patient's thymoma, we question whether the lymphoid component of the thymoma was also neoplastic or whether there were two distinct neoplasias-namely, epithelial lymphoma and $\mathrm{T}$ cell lymphoma. Occurrence of both $T$ cell and $B$ cell lymphomas within the thymus gland is well recognised. A normal immunophenotypic profile of thymoma thymocytes does not necessarily exclude $T$ cell lymphoma as it has been shown that the antigen phenotype of thymoma thymocytes is similar not only to that of normal thymocytes but also to that of the neoplastic cells of $T$ cell lymphoblastic lymphoma. ${ }^{11}$ Our case clearly shows this point as, despite the presence of a clonal $\mathrm{T}$ cell population, the immunophenotype of the thymoma tissue was that of a normal thymus.

There was a precipitous fall in the peripheral blood absolute lymphocyte count after surgery due largely to a decrease in circulating large granular lymphocytes. There was a corresponding fall in the bone marrow, accompanied by a resurgence of erythropoiesis. We postulate the following model to explain these observations. The clonal population of $T$ cells in the thymoma may have been secreting cytokine(s) which stimulated the polyclonal proliferation of large granular lymphocytes which in turn suppressed erythropoiesis. The removal of the source of the cytokine(s) by thymectomy would remove the stimulus to the large granular lymphocytes and hence the inhibition of erythropoiesis. The postulated reactive nature of the peripheral blood large granular lymphocytes would explain why we were unable to demonstrate clonality. Our findings are in contrast to a recent report of clonal $T$ cell populations in the peripheral blood in two out of three cases of PRCA, one of which was associated with $B$ cell chronic lymphocytic leukaemia (B CLL) and the other of which may have had early $B$ CLL. ${ }^{12}$

This case shows that the distinction between primary and secondary PRCA is no longer clear. Until now, patients in whom PRCA is associated with an absolute or relative $\mathrm{T}$ lymphocytosis have been included in the primary category. However, this patient had both an associated thymoma (putting it in the secondary category) as well as an absolute $\mathrm{T}$ lymphocytosis. We propose, therefore, that the term primary or idiopathic PRCA should be reserved for the small but significant minority of cases in whom no associated conditions or immune mediated suppression can be shown. Cases with an absolute $T$ cell lymphocytosis should therefore be included in the secondary category.

We thank Dr C G Geary (Manchester Royal Infirmary) for helpful comments, Mrs L Green (N W Regional Immunology Service) for performing the immunological studies, Dr G Corbitt (North Manchester Regional Virus Laboratory) for performing the HTLV1 virology, Dr F T Schutz (ICRF, Chester Beatty Laboratories) for HTLV1 molecular studies, and Miss Claire Peasgood and Mrs M Crichton Prince for typing the manuscript.

1 Ammus SS, Yunis AA. Acquired pure red cell aplasia. Am

2 Rosenow EC III, Hurley BT. Disorders of the thymus. A review. Arch Intern Med 1984;144:763-70.

3 Bailey RO, Dunn HG, Rubin AM, Ritaccio AL 
Myasthenia gravis with thymoma and pure red blood cell aplasia. Am $\mathcal{F}$ Clin Pathol 1988;89:687-93.

4 Loughran TP Jr, Starkebaum G. Large granular lymphocyte leukaemia. Report of 38 cases and review of the literature. Medicine (Balt) 1987;66:397-405.

5 Anonymous. Large granular lymphocytic leukaemia [editorial]. Lancet 1991;338:284-5.

6 Masaoka A, Hashimoto T, Shibata K, Yamakawa Y, Nakamae K, Ilzuka $M$. Thymomas associated with pure red cell aplasia. Histological and follow-up studies. Cancer, 1989;64:1872-8.

7 Starkebaum G, Loughran TP Jr, Kalyanaraman VS Kadin ME, Kidd PG, Singer JW, et al. Serum reactivity to HTLV-1 proteins in patients with large granular lymto HTLV-1 proteins in patients with large

8 Levitt LJ, Reyes GR, Moonka DK, Bensch K, Miller RA, Englemann EG. Human T cell leukaemia virus-1-associated T-suppressor cell inhibition of erythropoiesis in a patient with pure red cell aplasia and chronic $T$ gammalymphoproliferative disease. $f$ Clin Invest 1988;81: 538-48.

9 Ono A, Saito H, Kondo S, Yoshimatsu H, Tsuchiya M. RNA tumour virus in human thymomas and thymus hyperplasias. Semin Surg Oncol 1985;1:139-52.

10 Nidorf D, Saleem A. Immunosuppressive mechanisms in pure red cell aplasia-a review. Ann Clin Lab $S_{c i}$ 1990;20:214-19.

11 Murphy MF, Izaguirre CA, Dhaliwal H, Wrigley PFM, Waters AH. Pure red cell aplasia-evidence for an inhibitory action of the bone marrow adherent cell layer. inhibitory action of the bone marr

12 Vie H, Chevalier S, Gerand R, Moisan JP, Praloran V, Devilder MC, et al. Clonal expansion of lymphocytes bearing the $\gamma \delta \mathrm{T}$-cell receptor in a patient with large granular lymphocyte disorder. Blood 1989;74:285-90.

\title{
Concealed homicidal strangulation first discovered at necropsy
}

\author{
D W Sadler
}

\begin{abstract}
One adult and one childhood case of concealed homicide by strangulation are presented. Both cases were first recognised on formal neck dissection at necropsy. Neither showed any obvious external trauma to the neck or laryngeal fracture. External petechiae were absent in the child. The pattern of internal injuries in both cases suggested that the likely mechanism was strangulation. Particular care is required in busy routine medicolegal practice in order to detect deaths which are not immediately apparent as asphyxial.
\end{abstract}

$(F$ Clin Pathol 1994;47:679-680)

\section{Case reports}

CASE 1

The body of a 33 year old man was found lying face down on a country track. Although the first police officer on the scene had been concerned, the consensus view of CID officers and the police surgeon, after examining the body, both at the locus and stripped of clothing at the police mortuary, was of sudden natural death. The case was referred for routine medicolegal necropsy the following day. Occasional minor fresh abrasions were present on the forehead and elbows. There was a $4 \times 1 \mathrm{~mm}$ laceration to the frenulum of the upper lip. There were florid petechiae over the eyelids and conjunctivae. There were no externally apparent neck injuries. Neck dissection revealed bruising in the left platysma, sternomastoid, omohyoid and sternohyoid muscles, in both inferior pharyngeal constrictor muscles overlying the superior horns of the thyroid cartilage and over the upper right carotid sheath. The thyroid cartilage and hyoid bone were intact. There were florid mucosal haemorrhages, ranging from
1-7 mm, over the lateral and anterior walls of the oropharynx and posterior surface of the epiglottis. On the right edge of the tongue was an area of haemorrhage $8 \mathrm{~mm}$ in maximum dimension. Dissection of the back revealed fresh bruising within the back muscles, either side of T11 level and to the left of $\mathrm{L} 1$ level. No further trauma or any clinically relevant natural disease were identified at necropsy. Toxicological analyses were negative. The cause of death was given as "strangulation". After extensive police investigation and a Fatal Accident Inquiry the death is officially viewed as an unsolved homicide.

\section{CASE 2}

A 6 week old baby girl was found dead, lying face down on a couch after her mother was admitted to hospital for suspected self-poisoning. Suspicion of infanticide, rather than cot death, was raised when the mother recovered completely shortly after hospital admission. The child was well nourished and showed no external trauma. There was an abundant plume of yellow froth at the nostrils. There were no external petechiae. There were occasional petechiae over the visceral pleura, epicardium, and thymus. Neck dissection revealed two discrete areas of soft tissue bruising to the left upper neck, extending deeply around the digastric muscle and adjacent lymph nodes and becoming confluent over the carotid sheath and precervical fascia. Closer examination of the overlying skin revealed a bearly discernible $6 \mathrm{~mm}$ linear abrasion which became more obvious with drying over the next 24 hours. Dissection of the back of the neck revealed a $17 \times 13 \mathrm{~mm}$ horizontally aligned bruise straddling the midline within the upper trapezius muscle, $18 \mathrm{~mm}$ below the external occipital protruberance. No further trauma or natural disease was identified.

Microbiological screening and radiological 